\title{
Impeller Flow Field Laser Velocimeter Measurements
}

\author{
L. A. BROZOWSKI, T. V. FERGUSON and L. ROJAS \\ Rockwell International Corporation, Rocketdyne Division, Canoga Park, California
}

(Received August 9, 1995)

\begin{abstract}
Development of Computational Fluid Dynamics (CFD) computer codes for complex turbomachinery affords a complete three-dimensional (3-D) flow field description. While significant improvements in CFD have been made due to improvements in computers, numerical algorithms, and physical modeling, a limited experimental database for pump CFD code validation exists.

Under contract (NAS8-38864) to the National Aeronautics and Space Administration (NASA) at Marshall Space Flight Center (MSFC) a test program was undertaken at Rocketdyne to obtain benchmark data for typical rocket engine pump geometry. Nonintrusive velocity data were obtained with a laser two-focus velocimeter. Extensive laser surveys at the inlet and discharge of a Rocketdyne-designed impeller were performed. Static pressures were measured at key locations to provide boundary conditions for CFD code validation.
\end{abstract}

Key Words: Impeller flow; two-dimensional; laser velocimeter

\section{INTRODUCTION}

$\mathrm{D}$ evelopment of Computational Fluid Dynamics (CFD) computer codes for complex turbomachinery affords three-dimensional (3-D) flow field calculations. However, existing data for pump CFD code validation is limited. Accurate databases are required to validate the CFD codes to enable evaluation of existing turbulence models and grid number requirements.

Traditional flow field survey information from pressure sensors and directional probes are intrusive and typically yield an uncertainty in excess of $0.5 \%$ of full range and thus do not yield quality benchmark data. Pressure sensors and directional probes only yield circumferentially averaged information. Laser velocimetry is nonintrusive and yields accurate flow velocity and angle data. More importantly, laser velocimetry provides information at specific circumferential locations blade to blade.

The objective of the test program undertaken was to obtain benchmark quality data, flow velocity and angle at key locations in a generic pump operating at the impeller design flow rate. These data along with data from a similarly tested impeller $[1,2]$ will be used by the Consortium for Computational Fluid Dynamics Application in Propulsion Technology Pump Stage Team [3] to validate pump CFD codes.
The tested configuration consisted of a four-bladed unshrouded inducer, a shrouded impeller with six full blades and six partial blades, in conjunction with a diffusing crossover and discharge plenum. The flow field survey consisted of 10 radial stations along one axial plane at the impeller inlet, 11 axial stations in a radial plane immediately downstream of the impeller discharge, and 9 axial stations close to the crossover inlet. The fluid medium for the laser velocimeter surveys was ambient water.

Data are nondimensionalized as follows:

Nondimensional Length:

$$
\mathrm{L}_{\text {nondim }}=\frac{\mathrm{L}}{\mathrm{D}_{\text {tip }}}
$$

where:

\section{$\mathrm{L}$ is length}

$\mathrm{D}_{\text {tip }}$ impeller tip diameter

Nondimensional Head:

$$
\mathrm{H}_{\text {nondim }}=\frac{g_{c} \mathrm{H}}{\mathrm{U}_{\text {tip }}^{2}}
$$

where:

$\mathrm{H}$ is head

$\mathrm{g}_{\mathrm{c}}$ is the gravitational constant 
$\mathrm{U}_{\text {tip }}$ is the impeller discharge tip speed

Nondimensional Velocity:

$$
\mathrm{V}_{\text {nondim }}=\frac{\mathrm{V}}{\mathrm{U}_{\text {tip }}}
$$

where:

$\mathrm{V}$ is velocity

$\mathrm{U}_{\text {tip }}$ is the impeller discharge tip speed

\section{TEST ARTICLE}

The test article was a Rocketdyne-designed shrouded impeller that met the operational requirements for the Space Transportation Main Engine (STME) fuel pump and designated the "Consortium baseline impeller." Table 1 summarizes the impeller geometry and test conditions. Figure 1 provides a layout of the impeller blades.

The impeller was tested with an axial inlet and a four-bladed unshrouded inducer. The axial spacing between the inducer and impeller was intended to minimize the inducer wake effects at the impeller inlet while still providing enough critical speed margin for rotordynamic stability. Testing the impeller in conjunction with an axial inlet and inducer provided geometry typical of current rocket engine pumps.

While the test article geometry reflected current rocket engine designs, the impeller shroud wear ring clearance was purposely atypical of an engine. The nondimensional radial clearance between impeller shroud and the polypropylene seal was nominally -0.000166 . The radial interference fit minimized impeller discharge recirculation flow that may be more useful for validation of current CFD codes. This arrangement affords less complex CFD modeling since both the front and rear shroud recirculation zones can be eliminated.
The test configuration, presented in Figure 2, included a crossover discharge to minimize asymmetric flow at the impeller discharge.

\section{TEST FACILITY}

The test program was conducted in the Engineering Development Laboratory (EDL) Pump Test Facility (PTF) located at Rocketdyne's main facility in Canoga Park, California. A schematic of the flow loop is presented in Figure 3. The test article was driven by a 1,200-rpm, reversible, synchronous electric motor rated at $2,984 \mathrm{~kW}$. The motor was coupled to a $2,984-\mathrm{kW}$ gearbox capable of producing speeds of $6,322,8,013$, and $10,029 \mathrm{rpm}$. The pump CFD code validation configuration was tested at $6,322 \mathrm{rpm}$.

Water was supplied to the closed flow loop from a $28.769-\mathrm{m}^{3}$ stainless steel tank. The tank was rated at $1.0342 \mathrm{MPa}$ with a vacuum capability of $0.0962 \mathrm{MPa}$. A heat exchanger located adjacent to the tank maintained a uniform fluid inlet temperature. The flow rate to the tester was regulated by a throttle valve downstream of the pump. After passing through the throttle valve and into the tank, the flow passed through a series of baffles in the tank and was recirculated through the facility.

\section{TEST INSTRUMENTATION}

Two four-tap static piezometer rings were used to measure the inlet static pressure. They were located approximately 13.5 and 8.7 inlet pipe diameters upstream of the inducer. Water temperature was measured in the inlet line with a platinum wire filament temperature detector to allow calculation of the fluid density and vapor pressure.

Three impeller inlet static pressure measurements were aligned in one axial plane, but distributed around

TABLE 1

Design details of test article

\begin{tabular}{lcc}
\hline Parameter & Value \\
\hline Number of impeller full blades & 6 \\
Number of impeller partial blades & 6 \\
Nondimensional inlet eye diameter & 0.6633 \\
Shaft speed (rpm) & 6,322 \\
Impeller tip speed (m/s) & 76.0493 \\
Nondimensional impeller shroud wear ringradial clearance & -0.000166 \\
Impeller inlet design flow coefficient* & 0.144 \\
Nondimensional inducer tip radial clearance & 0.000967 \\
Nondimensional impeller B width & 0.078699 \\
Nondimensional impeller shroud thickness at discharge & 0.01393 \\
Nondimensional impeller hub thickness at discharge & 0.01739 \\
\hline
\end{tabular}

*Based on tester inlet flow and impeller eye speed. Does not take recirculation flow into account 


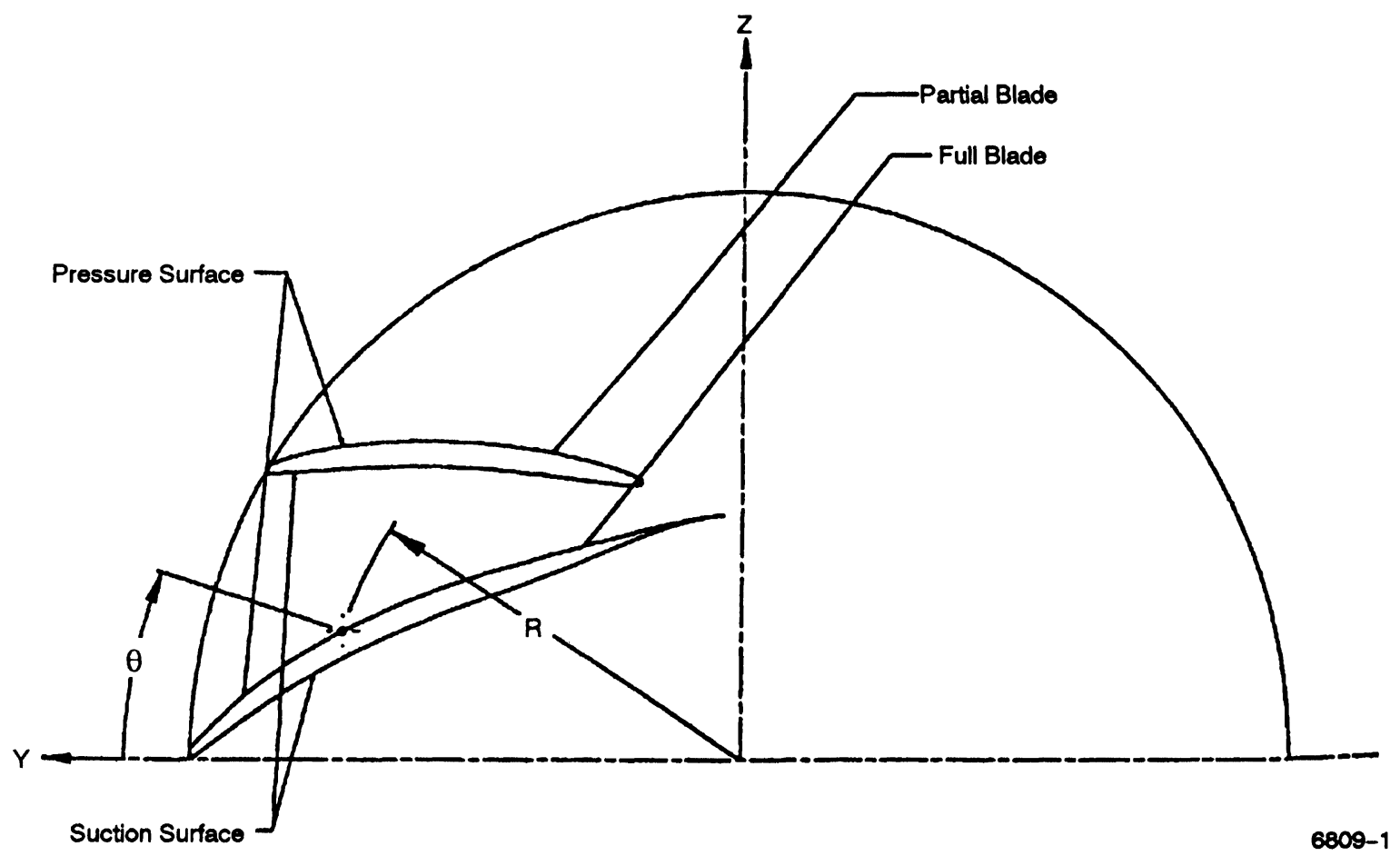

FIGURE 1 Impeller blade layout.

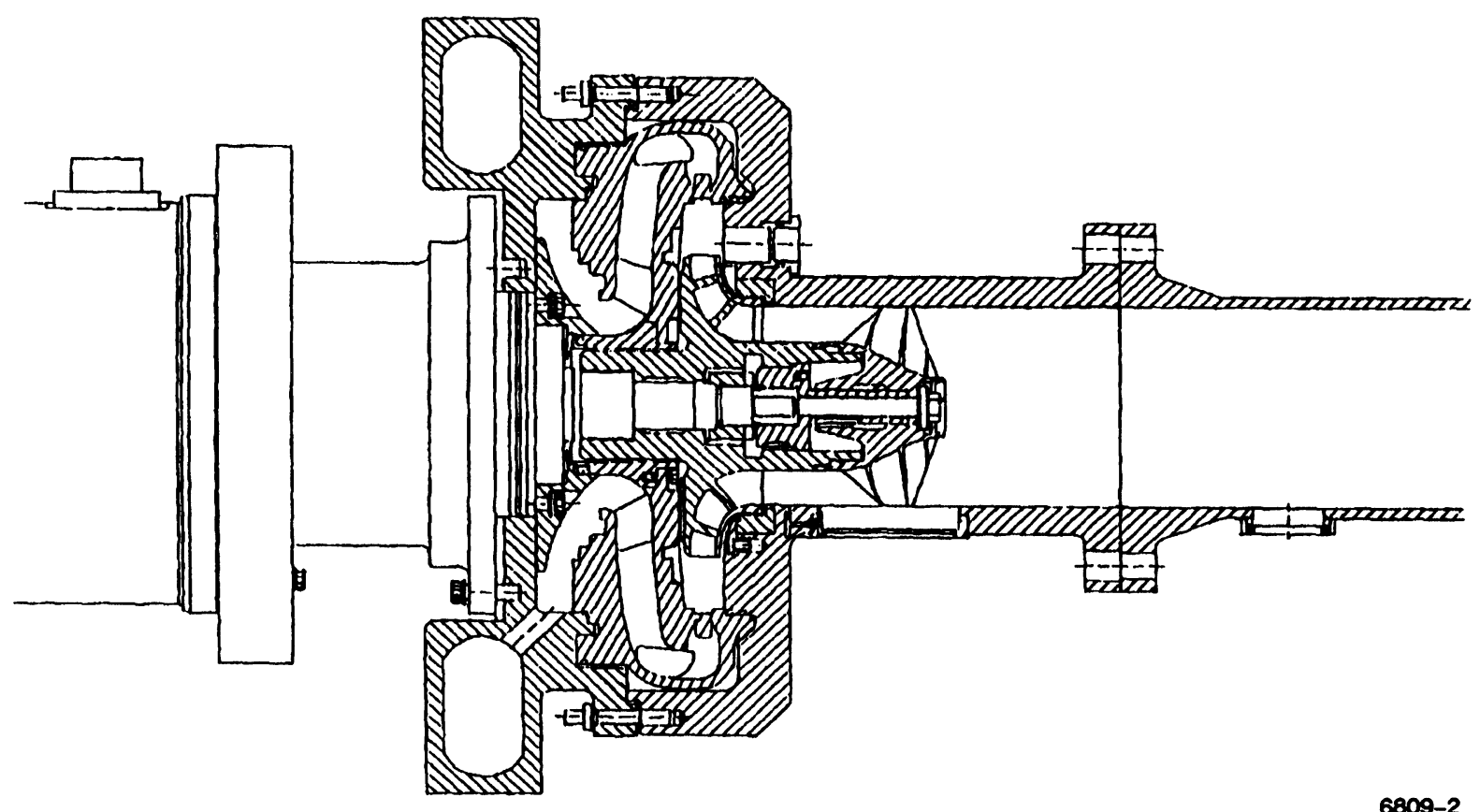

FIGURE 2 Tester configuration. 
the circumference ( 90 deg apart) to identify any circumferential pressure variations of impeller inlet flow. This identification is important because the impeller inlet laser survey occurs at one particular circumferential location. Circumferential variations are not reflected in the laser survey. The impeller inlet static pressure tap plane was located a nondimensional axial length of 0.0766 downstream of the laser survey plane.

Similarly, identification of circumferential variations at the impeller discharge was accommodated by three static pressure taps located around the tester circumference in a plane midway between the two impeller discharge laser survey planes. One static pressure tap was included at each of the two laser survey radial planes. A differential static pressure measurement between the lowest radial impeller discharge survey plane and the tester inlet provided redundancy. All pressure measurements were obtained with Taber full bridge strain gage transducers with an accuracy of $\pm 0.5 \%$ of full range. Flow rate was measured with one $20.32-\mathrm{cm}$ turbine-type flowmeter in the inlet line with measurement redundancy provided by another $20.32-\mathrm{cm}$ turbinetype flowmeter in the discharge line. Additional instrumentation was employed for facility monitoring and computer redlines.

\section{TEST PROGRAM}

The test program comprised a fiber-optic laser two-focus (L2F) velocimeter survey in one axial plane at the impeller inlet and two radial surveys at the impeller discharge. Table 2 lists the nondimensional radial positions of the impeller inlet survey referenced from the shaft centerline. The positions are also identified in terms of the percentage of the laser survey plane annulus height. With this designation, $0 \%$ is the hub and $100 \%$ is the laser window face on the inner diameter of the inlet housing. The nondimensional axial length between the laser survey plane and the impeller leading edge tip was -0.1290 . The negative sign indicates an axial location upstream of the axial reference zero. The laser velocimeter is capable of partitioning any given circumferential section into 16 separate data zones called "windows." For the tested configuration inlet survey, data were acquired over two adjacent 90 -deg segments. The survey was performed over 180 circumferential degrees because the inducer had four blades and the impeller had six full blades; it was not known a priori if inducer or impeller effects would dominate the flow field at the survey location. With 16 windows, data were segregated into distinct flow zones of 5.625-deg (90 deg/16 windows) angular sweep. An axial projection of a blade leading- edge tip intersection with the impeller shroud was used as the centerline of an impeller inlet timing mark which was machined into the impeller hub. This mark allowed triggering the start of the laser survey to be coincident with an impeller full blade. The center of the timing mark was used to commence circumferential laser velocimeter surveys at all annulus heights. Since adjacent 90-deg survey arcs were not similar in terms of impeller blade location, data were not ensemble averaged.

The impeller discharge surveys were performed at multiple axial locations along two radial planes. The nondimensional radial locations of the axial surveys were 0.5138 and 0.5597 . The plane located at a nondimensional radius of 0.5138 was immediately downstream of the impeller discharge. The plane located at a nondimensional radius of 0.5597 was the furthest downstream survey possible and at an approximate location of downstream components in actual hardware. Table 3 lists the laser survey nondimensional axial positions referenced from the impeller discharge tip shroud, $0.0 \%$ of impeller $B_{2}$ width. A negative value occurs when the axial location of the survey point is forward (toward the tester inlet) of the impeller discharge tip shroud. A value greater than $100 \%$ is indicative of a laser survey position at an axial distance toward the tester aft end, in excess of the impeller $\mathrm{B}_{2}$ width.

Encompassed in a 60-deg segment between two adjacent full blades at the impeller discharge is a partial blade. Circumferential partitioning over two adjacent 30-deg segments provided better circumferential flow definition between adjacent blades. With 16 windows, data were segregated into distinct flow zones of 1.875 $\operatorname{deg}(30 \mathrm{deg} / 16$ windows) of angular sweep. The impeller discharge timing mark centerline was located from an axial projection midway between the impeller suction and pressure surfaces at the impeller tip, $0 \%$ impeller $B_{2}$ width.

The center of the timing mark was used to commence circumferential laser velocimeter surveys at all axial survey locations. Adjacent 30-deg segments were not similar and ensemble averaging of the impeller discharge data was not performed.

Although the impeller inlet and discharge laser surveys spanned multiple test days and long time durations, a statistical analysis indicated that test-to-test parameter variations were negligible.

The tester shaft was marked and served to trigger the start of the laser velocimeter survey in the circumferential direction. This shaft mark was not necessarily coincident with the circumferential location of the timing mark machined at the inlet and discharge of the impeller. Therefore, the angular distance or equivalent time delay between the desired survey start and the laser start trigger 


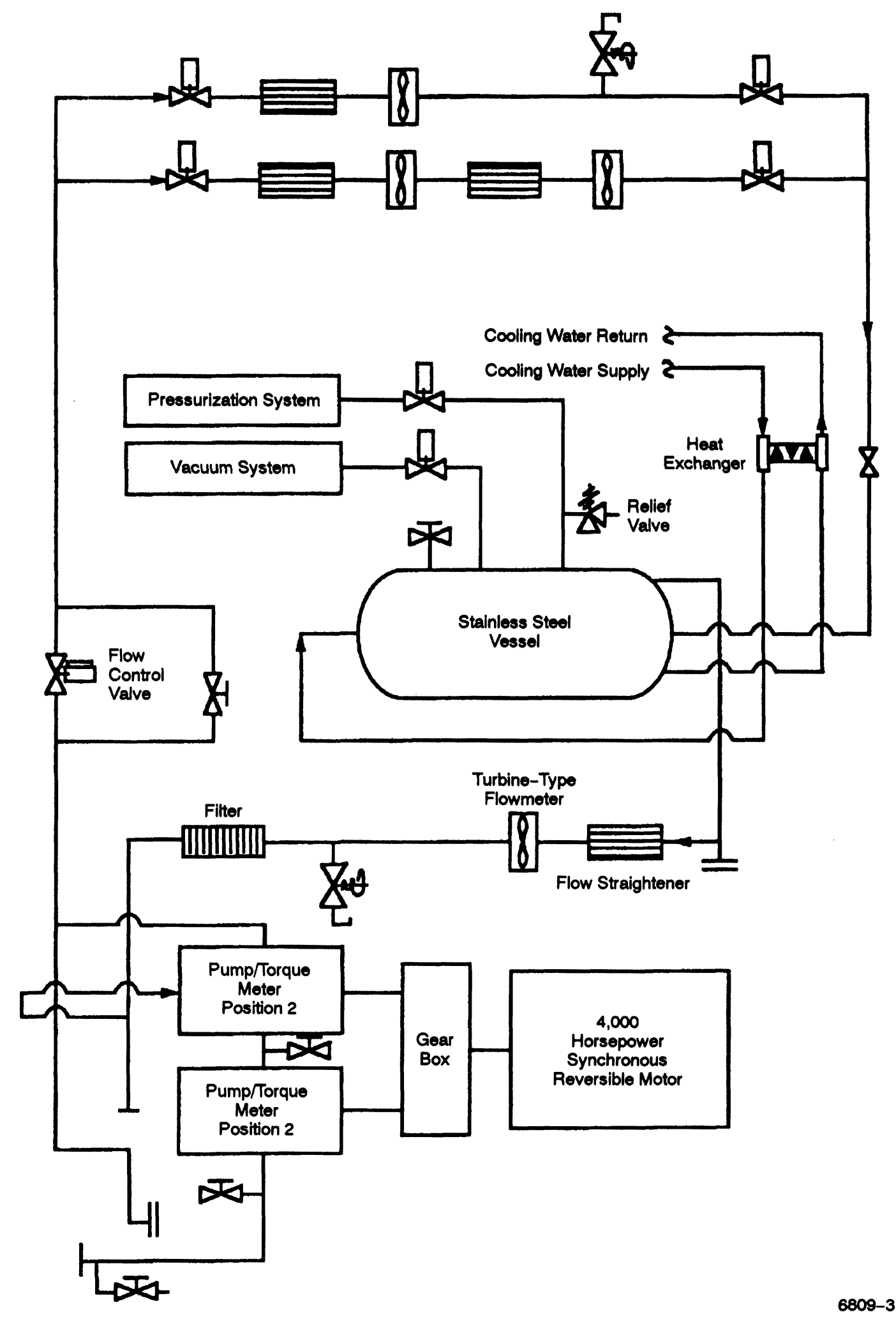

FIGURE 3 Engineering Development Laboratory Pump Test Facility-flow schematic. 
TABLE 2

Impeller inlet laser survey radial locations

\begin{tabular}{cc}
\hline Nondimensional radius & Percent impeller inlet annulus height \\
\hline 0.22731 & 10 \\
0.23317 & 15 \\
0.24489 & 25 \\
0.25660 & 35 \\
0.26832 & 45 \\
0.28004 & 55 \\
0.29176 & 65 \\
0.30348 & 75 \\
0.31520 & 85 \\
0.32692 & 95 \\
\hline
\end{tabular}

were determined. A photonic sensor was used to generate a once-per-revolution (OPR) pulse from the drive shaft of the tester. A timing mark was machined onto the impeller surface as described in the section entitled Test Program. The L2F was positioned so that the measurement volumes were able to detect the timing mark and generate a scattered light signal. The light signal was converted to an electronic signal via the L2F signal processing electronics. The phase angle between the occurrence of the OPR pulse and the timing mark pulse was determined.

The phase angle between the OPR pulse and the impeller inlet timing mark signal was also performed as the assembly rotated at full speed. Good agreement existed between the static and dynamic phase angle methods at both the impeller inlet and discharge locations.

\section{TEST RESULTS}

The impeller inlet laser velocimeter survey, which may serve as a boundary condition to CFD codes, also serves as a check for data integrity. Laser surveys over 180 circumferential degrees (two inducer blade passages or three impeller blade passages) were performed because of the dissimilar number of inducer and impeller blades. Laser data indicated inducer effects were prevalent and no significant impeller effects were evident in the flow. Data integrity was checked with a flow continuity match, i.e., a comparison of integrated flow based on the laser velocimeter velocities to flow measured with two turbine-type flowmeters. A continuity match of $98.6 \%$ was achieved at design flow coefficient. Discrepancies between integrated and measured flow may occur because of grid coarseness and/or use of a trapezoid integration scheme that does not include interpolation of the flow velocity to the walls. The continuity match was consistent with those calculated during previous test programs.
TABLE 3

Impeller discharge laser survey axial locations

\begin{tabular}{cc}
\hline $\begin{array}{c}\text { Nondimensional axial } \\
\text { location from reference }\end{array}$ & $\begin{array}{c}\text { Percent impeller } \\
\mathrm{B}_{2} \text { width }\end{array}$ \\
\hline \multicolumn{1}{c}{ Nondimensional radius $=0.5138$} & \\
0.15427 & -32.6 \\
0.16013 & -25.1 \\
0.18976 & 12.5 \\
0.19960 & 25.0 \\
0.20944 & 37.5 \\
0.21927 & 50.0 \\
0.22911 & 62.5 \\
0.23895 & 75.0 \\
0.24878 & 87.5 \\
0.26391 & 106.7 \\
0.27903 & 125.9 \\
0.15427 & \\
0.16013 & -32.6 \\
0.19304 & -25.1 \\
0.20616 & 16.7 \\
0.21927 & 33.3 \\
0.23239 & 50.0 \\
0.24551 & 66.7 \\
0.26094 & 83.3 \\
0.27638 & 102.9 \\
& 122.6 \\
\hline
\end{tabular}

Table 4 presents a summary of the impeller inlet flow characteristics for one of the 90 -deg surveys. The average values at each radial position were essentially the same for both 90 -deg circumferential surveys. The summary compiles nondimensional absolute velocity $(\mathrm{C} /$ $\left.\mathrm{U}_{\text {tip }}\right)$, nondimensional absolute tangential velocity $(\mathrm{Cu} /$ $\left.\mathrm{U}_{\text {tip }}\right)$, nondimensional absolute axial velocity $\left(\mathrm{Ca} / \mathrm{U}_{\text {tip }}\right)$, absolute flow angle, nondimensional relative velocity $\left(\mathrm{W} / \mathrm{U}_{\text {tip }}\right)$, nondimensional relative tangential velocity $\left(\mathrm{Wu} / \mathrm{U}_{\text {tip }}\right)$, and relative flow angle at each radial position surveyed. The values presented reflect flow-weighted nondimensional velocity, flow-weighted nondimensional tangential velocity, and area-weighted axial velocity. The other values were derived from these parameters. Bulk flow quantities were derived over all radii and represent average values for the entire flow. The hub to tip distribution of axial velocity is linear over most of the flow annulus, between 25 and $90 \%$ of impeller inlet annulus. Figures 4 and 5 present contour plots of the impeller inlet axial and tangential velocity components. The relative tangential velocity, axial velocity, and incidence angle at the impeller inlet are the parameters that affect the impeller discharge flow characteristics and hydrodynamic performance.

No significant circumferential pressure variations were detected at the impeller inlet. The variations measured were within transducer accuracy.

At the impeller discharge, the flow continuity match, calculated across the data locations within the impeller 
TABLE 4

Impeller inlet flow characteristics

NRA Pump CFD Code Validation Test

Laser Velocimeter surveys, ambient water, impeller inlet survey.

Test Number: t92a053,54,56

Test Date: October 1992

Impeller Inlet Data Set 1

Nondimensional Axial Plane: -0.1290

Impeller Inlet Flow Coefficient: $\quad 0.144$

Inducer:

ADP

Impeller:

Avg. Test Speed:

Arc Angle:

Orientation Angle:

Wall Avg. Static Head Coefficient:

Continuity Match \%:

Consortium Baseline

$6322 \mathrm{rpm}$

$90 \mathrm{deg}$

$1.63 \mathrm{deg}$

0.1568

98.64973

Overall Impeller Inlet Flow Characteristics

\begin{tabular}{ccccccccc}
\hline Radial Position & \% Annulus & $\begin{array}{c}\text { C/Utip } \\
\text { avg. }\end{array}$ & $\begin{array}{c}\text { Cu/Utip } \\
\text { avg. }\end{array}$ & $\begin{array}{c}\text { Ca/Utip } \\
\text { avg. }\end{array}$ & $\begin{array}{c}\text { Flow Ang. } \\
\text { (deg) }\end{array}$ & $\begin{array}{c}\text { W/Utip } \\
\text { avg. }\end{array}$ & $\begin{array}{c}\text { Wu/Utip } \\
\text { avg. }\end{array}$ & $\begin{array}{c}\text { Rel. Ang. } \\
\text { (deg) }\end{array}$ \\
\hline 1 & 10 & 0.2424 & 0.2079 & 0.1242 & 30.86 & 0.2763 & 0.2468 & 26.72 \\
2 & 15 & 0.2363 & 0.2015 & 0.1228 & 31.37 & 0.2919 & 0.2648 & 24.89 \\
3 & 25 & 0.2257 & 0.1913 & 0.1193 & 31.94 & 0.3214 & 0.2985 & 21.78 \\
4 & 35 & 0.2191 & 0.1876 & 0.1127 & 30.99 & 0.3445 & 0.3256 & 19.09 \\
5 & 45 & 0.2173 & 0.1906 & 0.1039 & 28.59 & 0.3613 & 0.3460 & 16.71 \\
6 & 55 & 0.2163 & 0.1946 & 0.0939 & 25.75 & 0.3774 & 0.3655 & 14.40 \\
7 & 65 & 0.2235 & 0.2067 & 0.0840 & 22.10 & 0.3860 & 0.3768 & 12.56 \\
8 & 75 & 0.2348 & 0.2220 & 0.0751 & 18.68 & 0.3922 & 0.3849 & 11.04 \\
9 & 85 & 0.2405 & 0.2312 & 0.0655 & 15.82 & 0.4045 & 0.3992 & 9.32 \\
10 & 95 & 0.2264 & 0.2195 & 0.0556 & 14.22 & 0.4379 & 0.4343 & 7.30 \\
\hline
\end{tabular}

Bulk flow-weighted quantities across inlet annulus

$\mathrm{Cu} /$ Utip:

$\mathrm{Ca} / \mathrm{Utip}:$

0.2038

0.0928

Flow Angle from Tangential: $\quad 24.49$

Wu/Utip:

Relative Flow Angle:

0.3370

15.40

Pump CFD Code Validation Tests Axial $=-0.1290$ Imp. In Flow Coeff $=0.144$

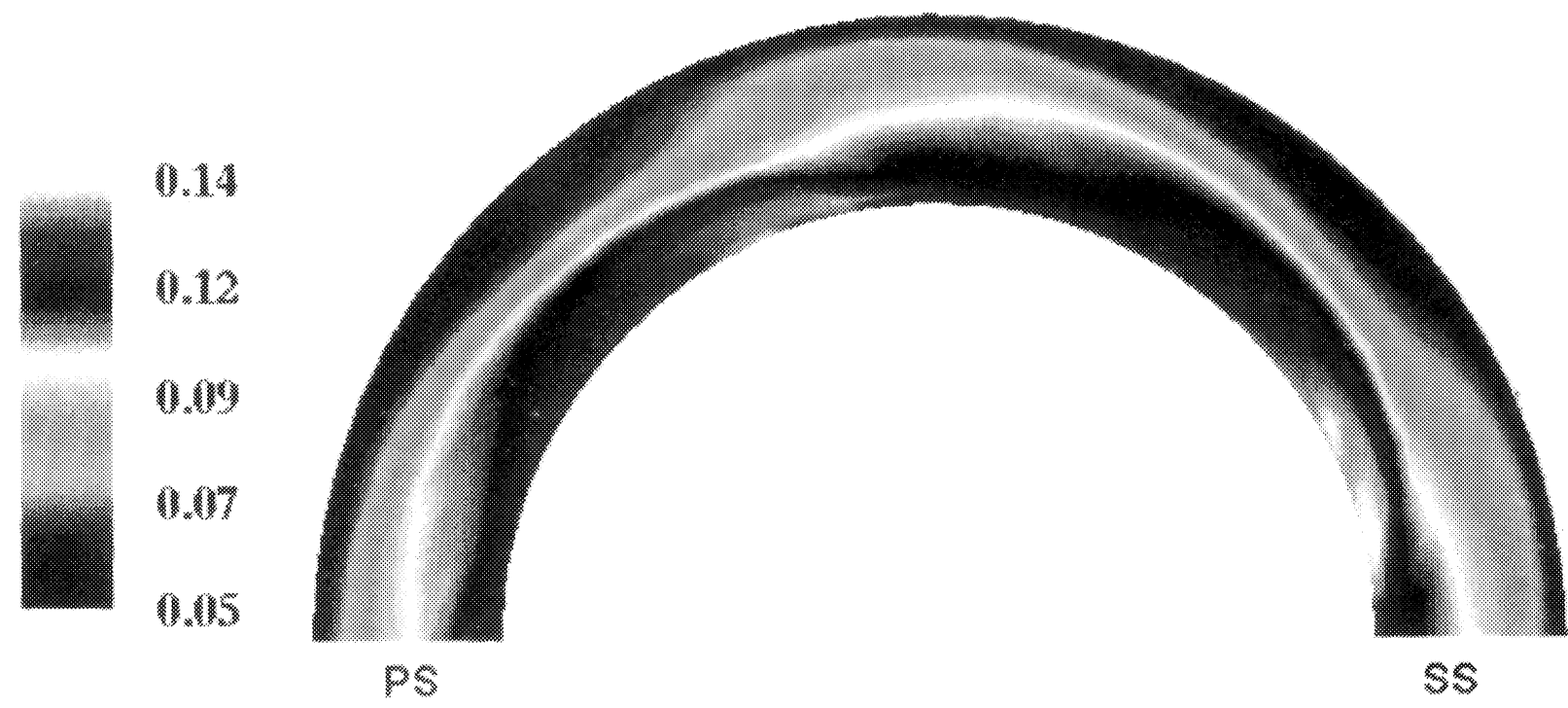

FIGURE 4 Consortium baseline impeller inlet laser survey (nondimensional axial velocity $\mathrm{Ca}$ ). 
Pump CFD Code Validation Tests Axial $=-0.1290 \mathrm{Imp}$. In Flow Coeff $=0.144$

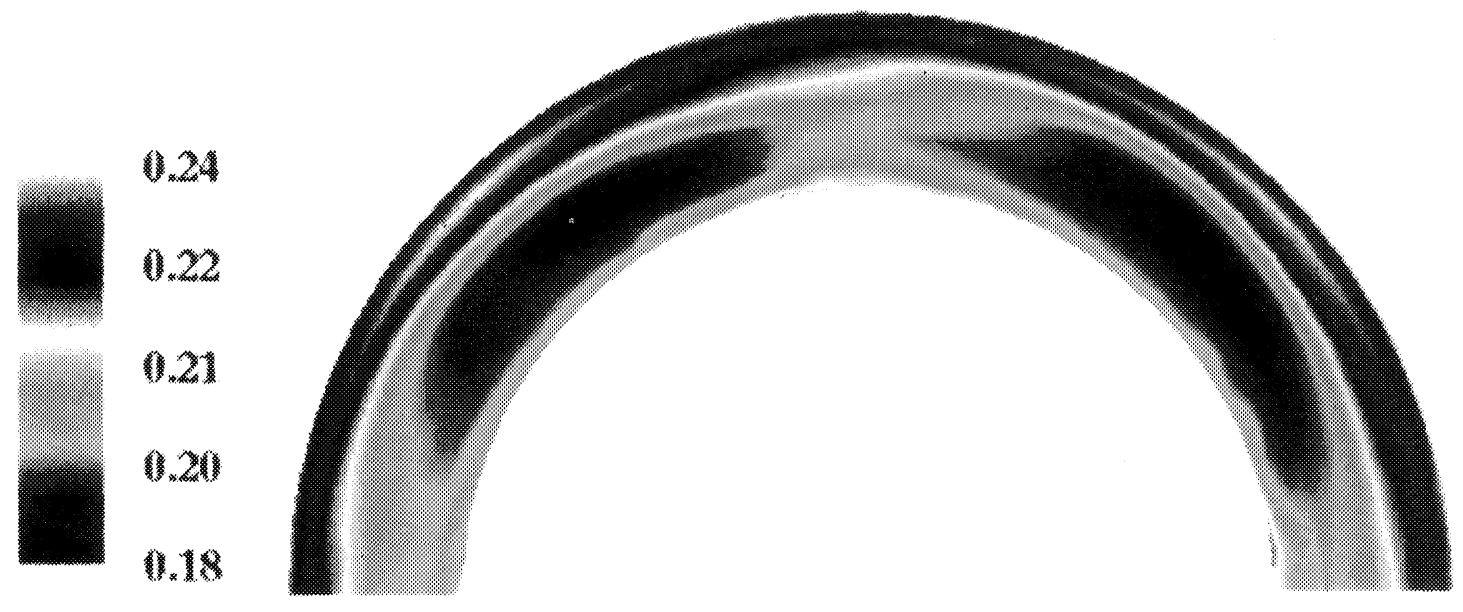

P\$

5

FIGURE 5 Consortium baseline impeller inlet laser survey (nondimensional tangential velocity $\mathrm{Cu}$ ).

TABLE 5

Impeller discharge flow characteristics

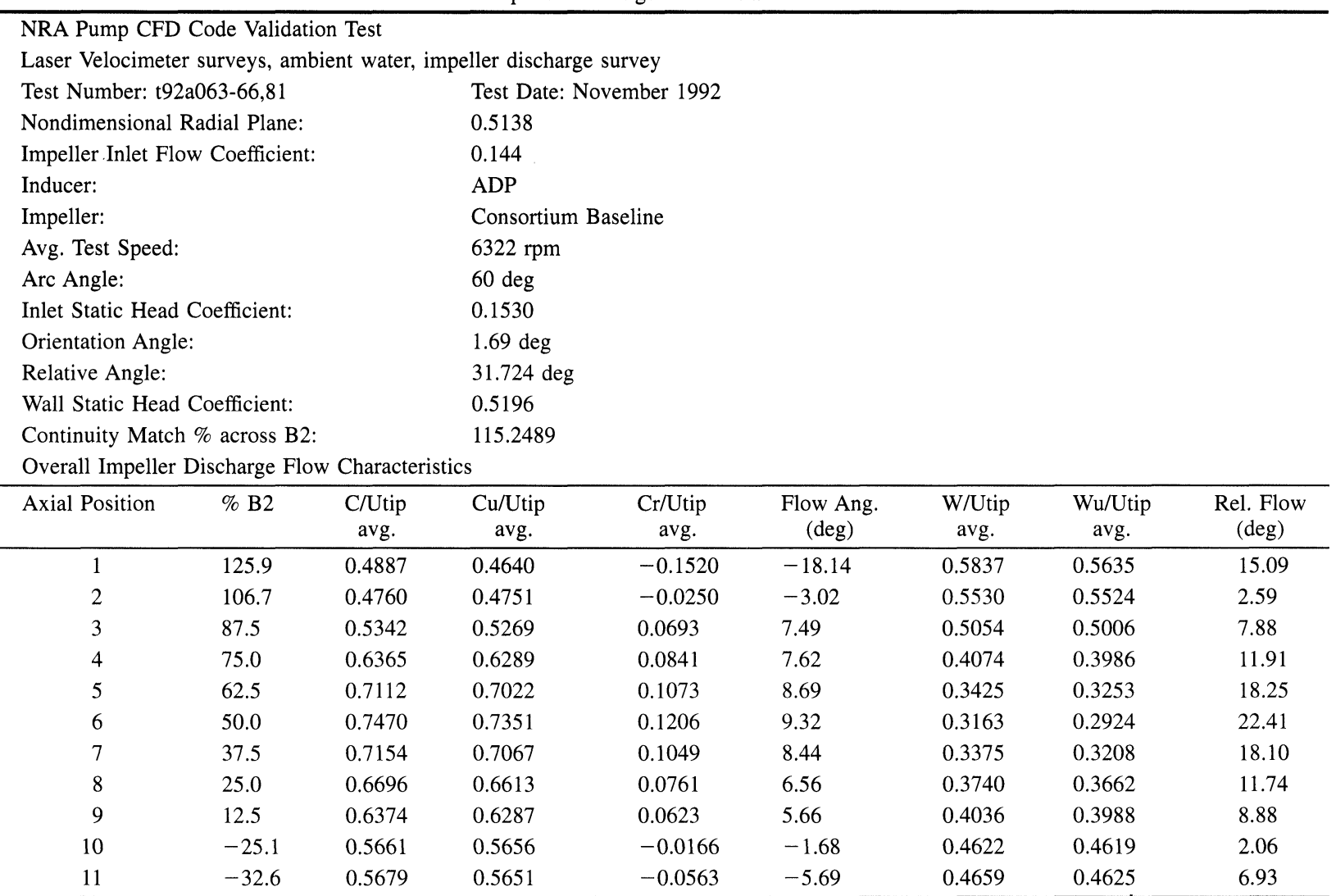

Bulk flow-weighted quantities across discharge plane

$\mathrm{Cu}$ /Utip: $\quad 0.8125$

Cr/Utip: $\quad 0.0265$

Flow Angle from Tangential: $\quad 1.87$

Wu/Utp: $\quad 0.2151$

Relative Flow Angle: $\quad 7.04$ 
$\mathrm{B}_{2}$ width, immediately downstream of the impeller, is $115.2 \%$. A number greater than $100 \%$ is attributed to laser survey grid coarseness coupled with the trapezoid integration method used to calculate the flow rate. At the plane located further downstream, calculated flow deviated only by $1 \%$ from the measured flow. This excellent continuity match is attributed to obtaining data that on the average represented the overall flow characteristics of the discharge channel.

Tables 5 and 6 present summaries of the impeller discharge flow characteristics for the two radial planes. Figures 6 and 7 present contour plots of flow absolute radial velocity and absolute tangential velocity components at the impeller discharge. Each of the contour plots contains data for the two radial planes. The plane on the left side is nearest to the impeller discharge.
From the presented plots, the impeller discharge wakes are clearly evident in the plane immediately downstream of the impeller. Regions of low radial velocity, absolute flow angle, and high tangential velocity extend over most of the axial region, hub to shroud, in the wake defect areas. At a radial plane further downstream from the impeller, this becomes less distinct since mixing causes the flow to become more uniform. The nondimensional radial velocity clearly shows secondary flow downward into the impeller shroud and hub clearance.

A circumferential variation in impeller discharge static head coefficient of $1.1 \%$ was measured. This value is slightly outside the range of transducer accuracy. The majority of circumferential variation in impeller discharge static head coefficient may be attributed to trans-

TABLE 6

Impeller discharge flow characteristics

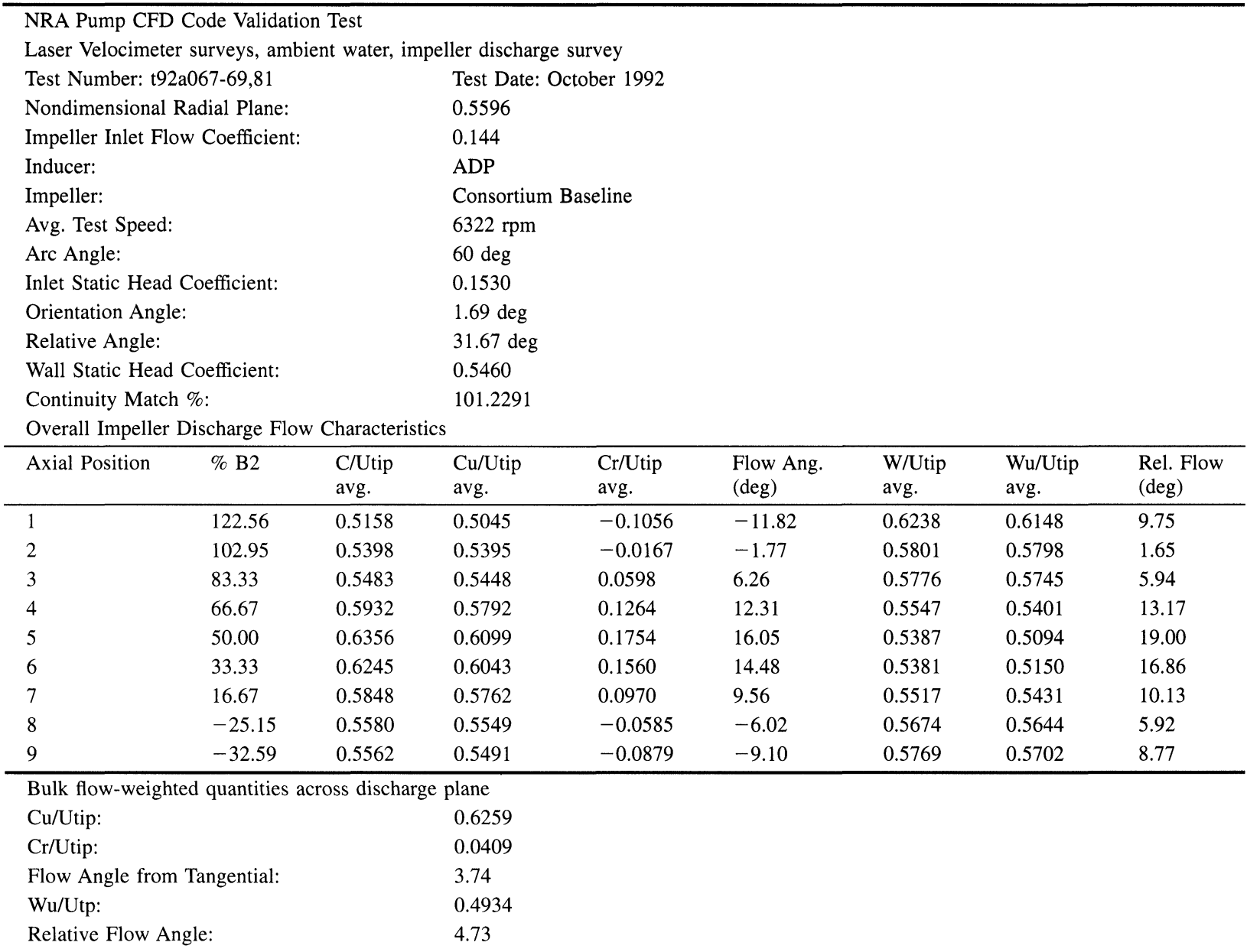




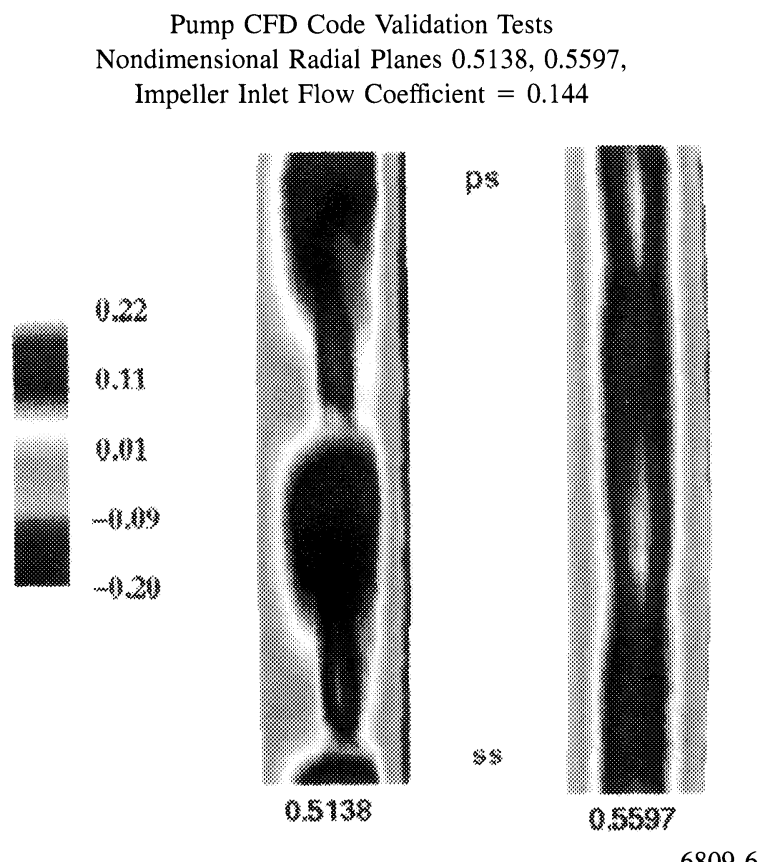

FIGURE 6 Consortium baseline impeller discharge laser survey (nondimensional radiál velocity $\mathrm{Cr}$ ).

ducer accuracy with a slight contribution caused by an asymmetric discharge flow condition. The crossover discharge was effective in eliminating the typical discharge flow asymmetry.

The impeller discharge laser survey traversed the impeller discharge channel while commencing in the same location circumferentially for each axial location. No attempt was made to alter the circumferential start location to coincide with the impeller full blade; thus, a rectangular grid results. A calculation was performed that defined which data windows corresponded to the individual flow passages in the plane immediately downstream of the impeller. In this manner a flow split among the two blade passages encompassed by the laser survey was performed. The passage between the first full blade and the partial blade was calculated to contain $49 \%$ of the total flow. The percent of calculated flow in the passage between the partial blade and the adjacent full blade was $51 \%$ of total flow. This type of uneven flow distribution, driven by secondary flow along the suction surface, was similarly exhibited in Reference [1].

\section{CONCLUSION}

A test program to obtain benchmark quality data for typical rocket engine pump geometry was successfully performed in Rocketdyne's EDL PTF. Data were obtained nonintrusively with a L2F velocimeter, static
Pump CFD Code Validation Tests Nondimensional Radial Planes 0.5138, 0.5597, Impeller Inlet Flow Coefficient $=0.144$
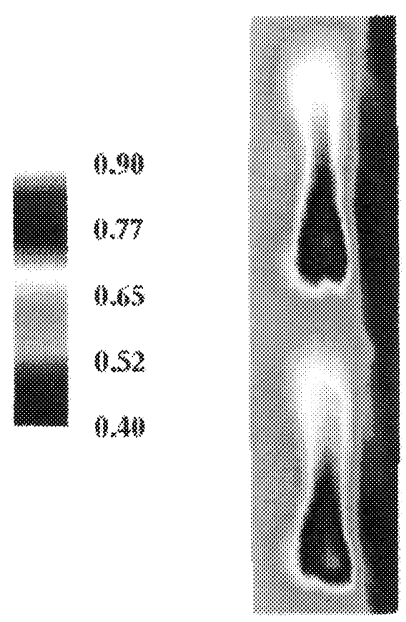

s

*

3

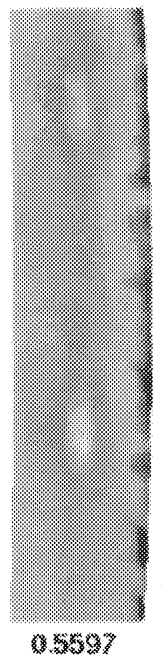

6809-7
FIGURE 7 Consortium baseline impeller discharge laser survey (nondimensional tangential velocity $\mathrm{Cu}$ ).

pressures were included at key locations to provide boundary conditions for CFD code validation. Laser surveys at the inlet and discharge of a Rocketdynedesigned impeller were performed. Repeatability of test conditions was demonstrated over the entire test duration.

The success of this empirical study adds significantly to the limited database of accurate centrifugal impeller flow field measurements. Further laser velocimeter surveys throughout various pump components will permit additional CFD code benchmarking data to be acquired and, ultimately, to a better understanding of fluid phenomena.

$\begin{array}{ll}\text { Nomenclature } & \\ B_{2} & \text { impeller passage discharge width } \\ C & \text { absolute velocity } \\ \mathrm{Ca} & \text { absolute axial velocity component } \\ C_{r} & \text { absolute radial velocity component } \\ C_{t} & \text { absolute tangential velocity component } \\ C_{u} & \text { absolute tangential velocity component } \\ U_{t i p} & \text { impeller tip tangential velocity }\end{array}$

\section{Acknowledgments}

The authors would like to acknowledge NASA-MSFC, with technical monitor Mr. Roberto Garcia, for funding the empirical study; Rocketdyne's Engineering Development Laboratory personnel, James J. Lesch, William L. Lowe, and Robert D. McGlynn for contributing to the 
success of the project and Michael R. Yandell for his design contributions and support during fabrication.

\section{References}

Brozowski, L. A., Ferguson, T. V., Lee, G. A., Prueger, G. H., and Rojas, L., "Laser Velocimeter Measurements of an Impeller Flow Field," ASME Fluids Engineering Conference Second Pumping
Machinery Symposium, June 1993a, Washington D.C., Vol. 154, pp. 187-196.

Brozowski, L. A., Ferguson, T. V., and Rojas, L., "Impeller Flow Field Characterization With a Laser Two-Focus Velocimeter," presented at the 11th Workshop for Computational Fluid Dynamics Applications in Rocket Propulsion, 20-22 April 1993b, Marshall Space Flight Center, Alabama.

Garcia, R., Jackson, E. D., and Schutzenhofer, L. A., "A Summary of the Activities of the NASA/MSFC Pump Stage Technology Team," 4th ISROMAC, April 1992, pp. 88-96. 

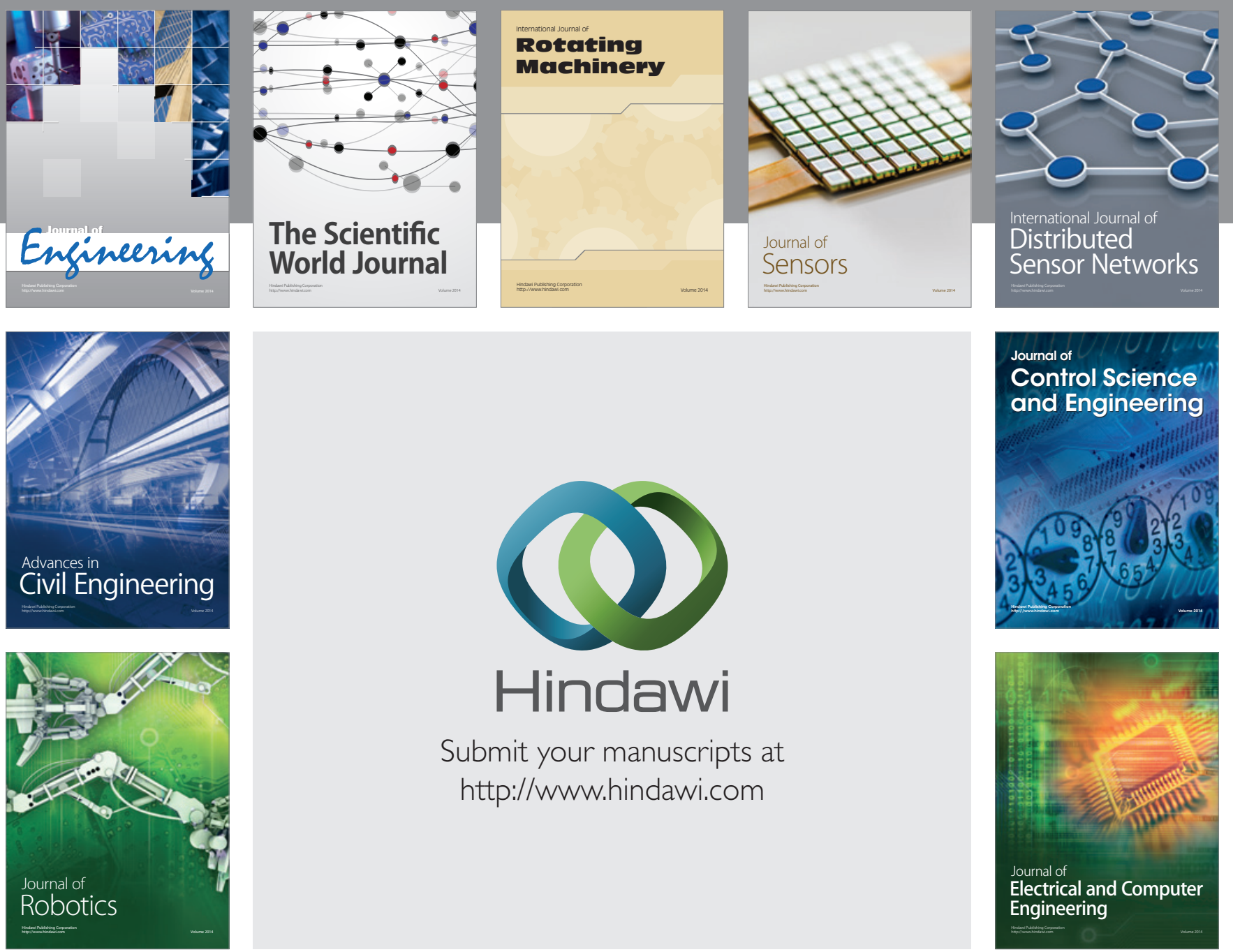

Submit your manuscripts at

http://www.hindawi.com
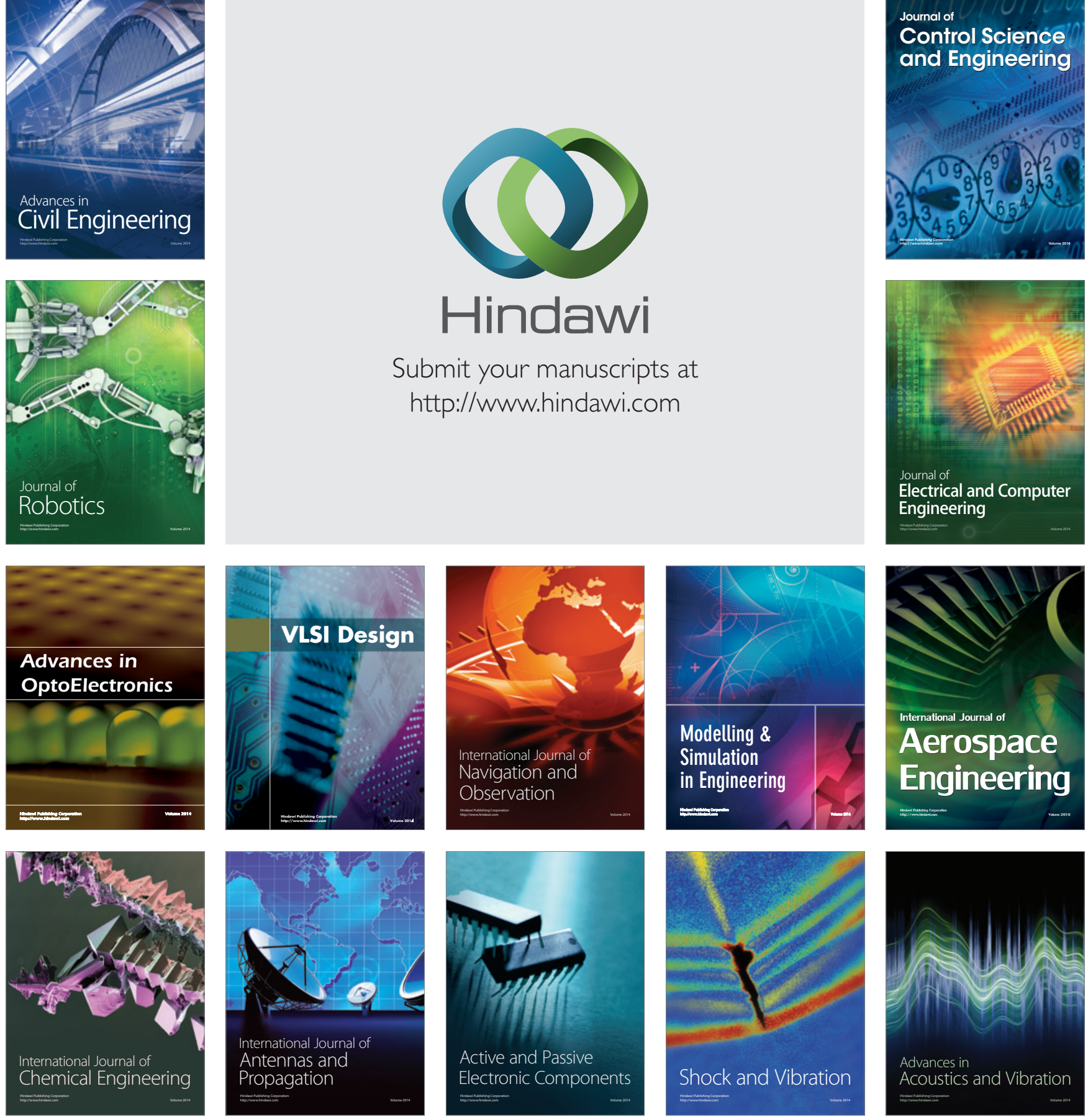